\title{
The prognostic value of pretreatment of systemic inflammatory responses in patients with urothelial carcinoma undergoing radical cystectomy
}

\author{
$\mathrm{J} \mathrm{H} \mathrm{Ku}^{1}, \mathrm{M} \mathrm{Kang}{ }^{1}, \mathrm{H} \mathrm{S} \mathrm{Kim}{ }^{1}$, C W Jeong ${ }^{1}, \mathrm{C} \mathrm{Kwak}{ }^{1}$ and $\mathrm{H} \mathrm{H} \mathrm{Kim}{ }^{\star}, 1$ \\ ${ }^{1}$ Department of Urology, Seoul National University College of Medicine, Seoul, Korea
}

Background: Systemic inflammatory response (SIR) is important in the relationship between the tumour, the host, and outcome in cancer patients. However, limited data exist regarding the prognostic significance of SIR in bladder cancer. We investigate the utility of pretreatment SIR in patients with urothelial carcinoma undergoing radical cystectomy.

Methods: The study cohort consisted of 419 patients with a median follow-up of 37.7 months. The SIRs used for each described prognostic nomogram are consistent with previously published data: C-reactive protein, albumin, white cell count, neutrophil count, lymphocyte count, and platelet count. Primary end point was disease-specific survival (DSS) and overall survival (OS) after surgery. Cox regression models were used to determine the time to disease-specific and overall mortality. Multivariate regression coefficients of the predictors were used to develop nomograms for predicting 5-year DSS and OS probability.

Results: Multivariate Cox regression analyses revealed that albumin, lymphocyte count, and platelet count were significantly associated with a significantly increased risk for death from bladder cancer. The nomograms including each index were developed to predict the probability of 5-year DSS and OS after radical cystectomy. The C statistics were $77.8 \%$ and $77.3 \%$, respectively, and exceeded the 2002 AJCC $(72.0 \%$ and $70.3 \%$, respectively). In the decision curve analyses, the nomograms including SIR demonstrated higher net benefit gains compared with the models without SIR.

Conclusions: Cellular components of SIR have better prognostic values compared with acute-phase protein in patients undergoing radical cystectomy for bladder cancer.

Radical cystectomy is the gold standard treatment for patients with high-risk non-muscle invasive or muscle-invasive bladder cancer. Despite this aggressive local approach, survival after surgery is highly dependent on the pathologic stage at the time of radical cystectomy. In patients with locally advanced disease, 5-year survival rates range from $26 \%$ to $64 \%$ (Stein et al, 2001). These poor outcomes highlight the need for continued advancements in risk stratification and proper selection of multimodal treatment approaches. However, risk stratification based on clinicopathological data alone is unlikely to be sufficient for optimal treatment decision-making (Canter et al, 2011). Lack of efficient prognostic biomarkers may be partly responsible for the high mortality rates caused by cancer. Therefore, novel prognostic markers and preoperative prediction models must improve the current ability to predict bladder cancer outcomes.

Increasing evidence supports the involvement of systemic inflammation in cancer development and progression (Mantovani et al, 2008). The systemic inflammatory response (SIR) is of considerable importance in the relationship between the tumour, the host, and outcome in patients with cancer. However, limited data exist regarding the potential prognostic significance of SIR in bladder cancer. We evaluated the prognostic significance of preoperative SIR and propose a novel risk prediction model in patients with urothelial carcinoma undergoing radical cystectomy.

*Correspondence: Professor HH Kim; E-mail: hhkim@snu.ac.kr

Received 11 August 2014; revised 6 November 2014; accepted 30 November 2014; published online 13 January 2015 


\section{MATERIALS AND METHODS}

The Institutional Review Board at our institution approved this study. We reviewed the electronic medical records for 433 patients who underwent radical cystectomy and pelvic lymphadenectomy for bladder cancer at Seoul National University Hospital from 1999 through 2011. Patients were excluded from the final analysis for the following reasons: pathological cell types other than urothelial cell carcinoma, established distant metastasis at radical cystectomy, and incomplete data.

Routine laboratory measurements were preoperatively performed. The coefficient of variation for these methods, over the range of measurement, was less than $5 \%$ as established by quality control procedures. The SIR used for each described prognostic nomogram is consistent with previously published literature: C-reactive protein (CRP), albumin, white cell count, neutrophil count, lymphocyte count, and platelet count. Glasgow prognostic score (GPS) (Forrest et al, 2003), modified GPS (mGPS) (McMillan, 2008), prognostic index (PI) (Kasymjanova et al, 2010), Onodera's Prognostic Nutritional Index (PNI) (Onodera et al, 1984), platelet/lymphocyte ratio (PLR) (Hwang et al, 2012), neutrophil/lymphocyte ratio (NLR) (Al Murri et al, 2006), and derived NLR (dNLR) (Proctor et al, 2012) were also constructed as described in Supplementary Table S1.

Surgical specimens were processed by a staff surgical pathologist at our institution according to standard procedures. Pathologic stage was assigned based on the 2002 American Joint Committee on Cancer (AJCC) staging system. Tumour grade was assessed according to the 2004 World Health Organization (WHO)/ International Society of Urologic Pathology consensus classifications. Lymphovascular invasion was defined as the unequivocal presence of tumour cells in an endothelium-lined space without underlying muscular walls. Positive margin status was defined as tumour presence at linked areas of soft tissue on the surgical specimen.

Patients were followed every 3-4 months for the first 2 years, every 6 months for the third and the fourth year, and annually thereafter. Follow-up consisted of physical examinations, serum chemistry evaluations, chest X-rays, renal ultrasound, and/or computed tomography scans. Details of the evaluation, surgery, pathologic review, and follow-up of these patients were previously described (Moon et al, 2014).
The primary end point was disease-specific survival (DSS) and overall survival (OS) after radical cystectomy. DSS was defined as the time from radical cystectomy to death from bladder cancer. The treating physicians determined the cause of death by chart review corroborated by death certificates, or by death certificates alone. Patient data were censored at the last follow-up or death if the event of interest had not been attained. All patients who were determined to have died of bladder cancer had progressive and widely disseminated metastases at the time of death. Peri-operative deaths occurring within 30 days of surgery were censored at the time of death for DSS analyses.

Cox regression models were used to determine the time to disease-specific mortality and all-cause mortality after radical cystectomy. All variables that were significant in univariate analyses were included in multivariate Cox's proportional hazards model. Multivariate regression coefficients of the predictor variables were used to develop nomograms. Proportional hazards assumptions were systemically verified using the GrambschTherneau residual based test (Grambsch et al, 1995).

To evaluate nomogram performance, we assessed both discrimination and calibration of these models. The discriminative ability of the model was quantitatively measured using the $\mathrm{C}$ statistic (Harrell et al, 1996). We used bootstrapping to obtain a relatively unbiased estimate. Confidence intervals (CIs) were obtained by creating 1000 bootstrap samples from the entire data set and replicating the estimation process. Discrimination of the nomograms was compared against that of the AJCC staging system. In the second step of the validation process, the relationship between the model-derived and actuarial outcome was graphically explored within calibration plots to explore nomogram performance. In the calibration plot, the 45-degree line represents perfect predictions. The validation was performed using 200 bootstrap resamples to decrease overfit bias. We conducted a decision curve analysis to assess the clinical usefulness of the prediction nomograms (Vickers and Elkin, 2006). Decision curve analysis evaluates the clinical net benefit of prediction models by summing the benefits (true positives) and subtracting the harms (false positives).

All statistical tests were performed using R 2.13.0 (R Development Core Team, Vienna, Austria, http://www.R-project.org) and SPSS software (SPSS, Chicago, IL, USA). Two-sided $P$ values $<0.05$ were considered statistically significant.

Table 1. Patient characteristics

Variables

Clinical

Gender (male/female)

Age, year (median, interquartile range)

Body mass index, $\mathrm{cm} \mathrm{kg}^{-2}$ (median, interquartile range)

American Society of Anesthesiologists score (1/2/3/4)

Year of surgery (1999-2006/2007-2011)

\section{Pathological}

Pathologic T stage (pT0/a/is/1/2/3/4)

Tumour grade (G0/low grade/high grade)

Lymphovascular invasion (absent/present)

Margin status (negative/positive)

Lymph node stage (N0/1/2/3)

\section{Inflammatory}

C-reactive protein, $\mathrm{mgl}^{-1}$ (median, interquartile range)

Albumin, $\mathrm{gl}^{-1}$ (median, interquartile range)

White cell count, $10^{9} \mathrm{I}^{-1}$ (median, interquartile range)

Neutrophil count, $10^{9} \mathrm{I}^{-1}$ (median, interquartile range)

Lymphocyte count, $10^{9} \mathrm{I}^{-1}$ (median, interquartile range)

Platelet count, $10^{9} \mathrm{I}^{-1}$ (median, interquartile range)

$362(86.4) / 57(13.6)$

$65.1,58.3-70.4$

$23.3,21.1-25.1$

$178(42.5) / 218(52.0) / 21(5.0) / 2(0.5)$

$145(34.6) / 274(65.4)$

$55(13.1) / 14(3.3) / 35(8.4) / 69(16.5) / 69(16.5) / 111(26.5) / 66$ (15.8)

$55(13.1) / 17(4.1) / 347(82.8)$

$279(66.6) / 140(33.4)$

$386(92.1) / 33(7.9)$

$324(77.3) / 36(8.6) / 49(11.7) / 10(2.4)$

Total

Data presented are number (\%) or median (interquartile range).
$3.5,1.0-10.7$

$41.0,38.0-44.0$

$6.2,5.1-7.9$

$3.6,2.8-4.8$

$1.7,1.3-2.1$

$223.0,185.0-270.0$

419 


\section{RESULTS}

The final study cohort consisted of 419 patients with a median follow-up of 37.7 months (interquartile range : 20.5-70.7 months, range: $0.1-176.2$ months). The median age at the time of cystectomy was 65.1 years (interquartile range: 58.3-70.4 years), and 362 $(86.4 \%)$ patients were male. Overall, 177 patients $(42.3 \%)$ had pT3/4 disease and $95(22.7 \%)$ had lymph node metastases. In total,
$205(48.9 \%)$ had $\left(\geqslant \mathrm{pT} 3 / \mathrm{N}_{\text {any }}\right.$ or $\left.\mathrm{pT}_{\text {any }} / \mathrm{N}+\right)$ disease. Table 1 describes the cohort characteristics. Overall, 133 patients (31.7\%) died; of these, 98 (23.3\%) died of bladder cancer. Actuarial OS probabilities were $80.6 \%$ (95\% CI, 76.7-84.5\%), 64.4\% (95\% CI, 59.1-69.7\%), and $60.0 \%$ (95\% CI, 54.1-65.9\%) at 2, 5, and 8 years after cystectomy, respectively. Actuarial DSS probabilities were $84.7 \%$ (95\% CI, $81.2-88.2 \%$ ), $71.9 \%$ (95\% CI, 66.8-77.0\%), and 68.3\% (95\% CI, $62.6-74.0 \%)$ at 2,5 , and 8 years after cystectomy, respectively.

Table 2. Univariate and multivariate Cox proportional hazard regression analyses of disease-specific survival

\begin{tabular}{|c|c|c|c|c|}
\hline \multirow[b]{3}{*}{ Variables } & \multicolumn{4}{|c|}{ Hazard ratio ( $95 \%$ confidence interval) } \\
\hline & \multicolumn{2}{|c|}{ Univariate } & \multicolumn{2}{|c|}{ Multivariate } \\
\hline & & $P$ value & & $P$ value \\
\hline \multicolumn{5}{|l|}{ Clinical } \\
\hline $\begin{array}{l}\text { Gender } \\
\text { Male } \\
\text { Female }\end{array}$ & $\begin{array}{c}\text { Reference } \\
0.867(0.463-1.623)\end{array}$ & 0.668 & & \\
\hline $\begin{array}{l}\text { Age, years } \\
<65 \\
\geqslant 65\end{array}$ & $\begin{array}{c}\text { Reference } \\
1.840(1.229-2.755)\end{array}$ & 0.003 & $\begin{array}{c}\text { Reference } \\
2.061(1.344-3.162)\end{array}$ & 0.001 \\
\hline $\begin{array}{l}\text { Body mass index, } \mathrm{cm} \mathrm{kg}^{-2} \\
<25 \\
\geqslant 25\end{array}$ & $\begin{array}{c}\text { Reference } \\
0.674(0.418-1.087)\end{array}$ & 0.106 & & \\
\hline $\begin{array}{l}\text { American Society of Anesthesiologists score } \\
1 \\
\geqslant 2\end{array}$ & $\begin{array}{c}\text { Reference } \\
1.115(0.750-1.658)\end{array}$ & 0.579 & & \\
\hline $\begin{array}{l}\text { Year of surgery } \\
1999-2006 \\
2007-2011\end{array}$ & $\begin{array}{c}\text { Reference } \\
0.789(0.522-1.192)\end{array}$ & 0.261 & & \\
\hline \multicolumn{5}{|l|}{ Pathological } \\
\hline $\begin{array}{l}\text { pT stage } \\
\leqslant \text { pT2 } \\
\geqslant \text { pT3 }\end{array}$ & $\begin{array}{c}\text { Reference } \\
3.551(2.350-5.368)\end{array}$ & $<0.001$ & $\begin{array}{c}\text { Reference } \\
1.836(1.136-2.967)\end{array}$ & 0.013 \\
\hline $\begin{array}{l}\text { Tumour grade } \\
\text { Low grade } \\
\text { High grade }\end{array}$ & $\begin{array}{c}\text { Reference } \\
3.384(1.569-7.302)\end{array}$ & 0.001 & $\begin{array}{c}\text { Reference } \\
1.706(0.700-4.160)\end{array}$ & 0.240 \\
\hline $\begin{array}{l}\text { Lymphovascular invasion } \\
\text { Absent } \\
\text { Present }\end{array}$ & $\begin{array}{c}\text { Reference } \\
3.423(2.295-5.104)\end{array}$ & $<0.001$ & $\begin{array}{c}\text { Reference } \\
1.746(1.094-2.785)\end{array}$ & 0.019 \\
\hline $\begin{array}{l}\text { Margin status } \\
\text { Negative } \\
\text { Positive }\end{array}$ & $\begin{array}{c}\text { Reference } \\
2.678(1.545-4.643)\end{array}$ & 0.001 & $\begin{array}{c}\text { Reference } \\
1.668(0.915-3.041)\end{array}$ & 0.095 \\
\hline $\begin{array}{l}\mathrm{pN} \text { stage } \\
\mathrm{N}- \\
\mathrm{N}+\end{array}$ & $\begin{array}{c}\text { Reference } \\
4.186(2.808-6.239) \\
\end{array}$ & $<0.001$ & $\begin{array}{c}\text { Reference } \\
2.839(1.844-4.372)\end{array}$ & $<0.001$ \\
\hline \multicolumn{5}{|l|}{ Inflammatory } \\
\hline $\begin{array}{l}\text { C-reactive protein, } \mathrm{mg} \mathrm{I}^{-1} \\
0(\leqslant 10) \\
1(>10)\end{array}$ & $\begin{array}{c}\text { Reference } \\
1.111(0.577-2.138)\end{array}$ & 0.753 & & \\
\hline Albumin, $\mathrm{gl}^{-1}$ & & 0.001 & & 0.046 \\
\hline $\begin{array}{l}0(\geqslant 35) \\
1(<35)\end{array}$ & $\begin{array}{c}\text { Reference } \\
2.443(1.428-4.181)\end{array}$ & & $\begin{array}{c}\text { Reference } \\
1.794(1.010-3.187)\end{array}$ & \\
\hline $\begin{array}{l}\text { White cell count, }\left.10^{9}\right|^{-1} \\
0(\leqslant 11) \\
1(>11)\end{array}$ & $\begin{array}{c}\text { Reference } \\
1.442(0.631-3.294)\end{array}$ & 0.385 & & \\
\hline $\begin{array}{l}\text { Neutrophil count, }\left.10^{9}\right|^{-1} \\
0(<7.5) \\
1(\geqslant 7.5)\end{array}$ & $\begin{array}{c}\text { Reference } \\
1.773(0.921-3.410)\end{array}$ & 0.086 & & \\
\hline $\begin{array}{l}\text { Lymphocyte count, } 10^{9} \mathrm{I}^{-1} \\
0(\geqslant 1.0) \\
1(<1.0)\end{array}$ & $\begin{array}{c}\text { Reference } \\
2.154(1.080-4.296)\end{array}$ & 0.029 & $\begin{array}{c}\text { Reference } \\
2.436(1.201-4.94)\end{array}$ & 0.014 \\
\hline $\begin{array}{l}\text { Platelet count, }\left.10^{9}\right|^{-1} \\
0(<400) \\
1(\geqslant 400)\end{array}$ & $\begin{array}{c}\text { Reference } \\
2.390(1.203-4.747)\end{array}$ & 0.013 & $\begin{array}{c}\text { Reference } \\
2.110(1.017-4.379)\end{array}$ & 0.045 \\
\hline
\end{tabular}


The univariate and multivariate analysis results are shown in Tables 2 and 3. Among the clinicopathological variables, age, pT stage, tumour grade, lymphovascular invasion, margin status, and $\mathrm{pN}$ stage were associated with increased risk of disease-specific mortality in univariate analysis $(P<0.05)$. Among inflammatory variables, albumin, lymphocyte count, and platelet count were significantly associated with DSS; however, CRP, white cell count, and neutrophil count were not associated with DSS. We next assessed the association of inflammatory variables and diseasespecific mortality while controlling for clinicopathological variables identified at the time of radical cystectomy. Multivariate Cox regression analyses revealed that preoperative albumin (hazard ratio (HR), 1.79; 95\% CI, 1.01-3.19), lymphocyte count (HR, 2.44; 95\% CI, 1.20-4.94), and platelet count (HR, 2.11; 95\% CI, 1.02-4.38) remained independently associated with a significantly increased risk for death from bladder cancer (Table 2). Preoperative albumin

Table 3. Univariate and multivariate Cox proportional hazard regression analyses of overall survival

\begin{tabular}{|c|c|c|c|c|}
\hline \multirow[b]{3}{*}{ Variables } & \multicolumn{4}{|c|}{ Hazard ratio (95\% confidence interval) } \\
\hline & \multicolumn{2}{|c|}{ Univariate } & \multicolumn{2}{|c|}{ Multivariate } \\
\hline & & $P$ value & & $P$ value \\
\hline \multicolumn{5}{|l|}{ Clinical } \\
\hline $\begin{array}{l}\text { Gender } \\
\text { Male } \\
\text { Female }\end{array}$ & $\begin{array}{c}\text { Reference } \\
0.942(0.548-1.559)\end{array}$ & 0.768 & & \\
\hline $\begin{array}{l}\text { Age, years } \\
\quad<65 \\
\geqslant 65\end{array}$ & $\begin{array}{c}\text { Reference } \\
2.146(1.507-3.055)\end{array}$ & $<0.001$ & $\begin{array}{c}\text { Reference } \\
2.425(1.662-3.537)\end{array}$ & $<0.001$ \\
\hline $\begin{array}{l}\text { Body mass index, } \mathrm{cm} \mathrm{kg}^{-2} \\
<25 \\
\geqslant 25\end{array}$ & $\begin{array}{c}\text { Reference } \\
0.591(0.386-0.903)\end{array}$ & 0.015 & $\begin{array}{c}\text { Reference } \\
0.687(0.444-1.064)\end{array}$ & 0.093 \\
\hline $\begin{array}{l}\text { American Society of Anesthesiologists score } \\
1 \\
\geqslant 2\end{array}$ & $\begin{array}{c}\text { Reference } \\
1.357(0.953-1.924)\end{array}$ & 0.086 & & \\
\hline $\begin{array}{l}\text { Year of surgery } \\
\text { 1999-2006 } \\
\text { 2007-2011 }\end{array}$ & $\begin{array}{c}\text { Reference } \\
1.063(0.739-1.527)\end{array}$ & 0.743 & & \\
\hline \multicolumn{5}{|l|}{ Pathological } \\
\hline $\begin{array}{l}\text { pT stage } \\
\leqslant \text { pT2 } \\
\geqslant \text { pT3 }\end{array}$ & $\begin{array}{c}\text { Reference } \\
3.730(2.601-5.349)\end{array}$ & $<0.001$ & $\begin{array}{c}\text { Reference } \\
2.567(1.653-3.984)\end{array}$ & $<0.001$ \\
\hline $\begin{array}{l}\text { Tumour grade } \\
\text { Low grade } \\
\text { High grade }\end{array}$ & $\begin{array}{c}\text { Reference } \\
2.151(1.236-3.745)\end{array}$ & 0.007 & $\begin{array}{c}\text { Reference } \\
0.980(0.518-1.854)\end{array}$ & 0.951 \\
\hline $\begin{array}{l}\text { Lymphovascular invasion } \\
\text { Absent } \\
\text { Present }\end{array}$ & $\begin{array}{c}\text { Reference } \\
2.658(1.890-3.739)\end{array}$ & $<0.001$ & $\begin{array}{c}\text { Reference } \\
1.359(0.901-2.051)\end{array}$ & 0.143 \\
\hline $\begin{array}{l}\text { Margin status } \\
\text { Negative } \\
\text { Positive }\end{array}$ & $\begin{array}{c}\text { Reference } \\
2.607(1.602-4.242)\end{array}$ & $<0.001$ & $\begin{array}{c}\text { Reference } \\
1.756(1.047-2.946)\end{array}$ & 0.033 \\
\hline $\begin{array}{l}\mathrm{pN} \text { stage } \\
\mathrm{N}- \\
\mathrm{N}+\end{array}$ & $\begin{array}{c}\text { Reference } \\
3.133(2.204-4.454)\end{array}$ & $<0.001$ & $\begin{array}{c}\text { Reference } \\
2.194(1.491-3.226)\end{array}$ & $<0.001$ \\
\hline \multicolumn{5}{|l|}{ Inflammatory } \\
\hline $\begin{array}{l}\text { C-reactive protein, } \mathrm{mgl}^{-1} \\
0(\leqslant 10) \\
1(>10)\end{array}$ & $\begin{array}{c}\text { Reference } \\
1.095(0.637-1.884)\end{array}$ & 0.742 & & \\
\hline $\begin{array}{l}\text { Albumin, } \mathrm{gl}^{-1} \\
0(\geqslant 35) \\
1(<35)\end{array}$ & $\begin{array}{c}\text { Reference } \\
2.961(1.924-4.555)\end{array}$ & $<0.001$ & $\begin{array}{c}\text { Reference } \\
1.670(1.007-2.767)\end{array}$ & 0.047 \\
\hline $\begin{array}{l}\text { White cell count, }\left.10^{9}\right|^{-1} \\
0(\leqslant 11) \\
1(>11)\end{array}$ & $\begin{array}{c}\text { Reference } \\
1.412(0.690-2.886)\end{array}$ & 0.345 & & 0.508 \\
\hline $\begin{array}{l}\text { Neutrophil count, }\left.10^{9}\right|^{-1} \\
0(<7.5) \\
1(\geqslant 7.5)\end{array}$ & $\begin{array}{c}\text { Reference } \\
1.839(1.057-3.200)\end{array}$ & 0.031 & $\begin{array}{c}\text { Reference } \\
1.243(0.652-2.368)\end{array}$ & \\
\hline $\begin{array}{l}\text { Lymphocyte count, } 10^{9} \mathrm{I}^{-1} \\
0(\geqslant 1.0) \\
1(<1.0)\end{array}$ & $\begin{array}{c}\text { Reference } \\
2.465(1.410-4.311)\end{array}$ & 0.002 & $\begin{array}{c}\text { Reference } \\
2.700(1.511-4.825)\end{array}$ & 0.001 \\
\hline $\begin{array}{l}\text { Platelet count, }\left.10^{9}\right|^{-1} \\
0(<400) \\
1(\geqslant 400)\end{array}$ & $\begin{array}{c}\text { Reference } \\
2.780(1.597-4.842)\end{array}$ & $<0.001$ & $\begin{array}{c}\text { Reference } \\
2.022(1.082-3.779)\end{array}$ & 0.027 \\
\hline
\end{tabular}


(HR, 1.67; 95\% CI, 1.01-2.77), lymphocyte count (HR, 2.70; 95\% CI, 1.51-4.83), and platelet count (HR, 2.02; 95\% CI, 1.08-3.78) were also independent prognostic predictors of OS (Table 3 ).

The nomograms predicting the probability of 2- and 5-year DSS and OS after radical cystectomy are shown in Figure 1. The C statistic of the 2002 AJCC for DSS and OS was $72.0 \%$ and $70.3 \%$, respectively. Addition of SIR increased the predictive accuracy of the 2002 AJCC. The accuracy of nomograms was $77.8 \%$ and $77.3 \%$, respectively, and exceeded that of the 2002 AJCC (Table 4). Figure 2 shows the calibration plots of the nomograms. Assessment of the nomogram axes indicated that the performance characteristics are virtually parallel to the observed disease-specific mortality rates and close to ideal predictions, shown by the 45-degree line. In the decision curve analysis, the nomograms including SIR demonstrated higher net benefit gains throughout the entire range of threshold probabilities for disease-specific mortality after 5 years compared with the models without SIR (Figure 3).

The relationships between the constructed SIR-based prognostic scores and outcomes are shown in Supplementary Figures S1 and S2, respectively. Elevated cellular components of SIR (PNI, PLR, NLR, and dNLR) were associated with a reduced DSS and OS (all $P<0.05)$, whereas acute-phase protein-based prognostic scores (GPS, mGPS, and PI) were not.

When the constructed SIR-based prognostic scores were included, the univariate and multivariate analysis results are shown in Supplementary Tables S2 and 3. Among inflammatory variables, PNI, PLR, NLR, and dNLR were significantly associated with DSS; however, mGPS and PI were not associated with DSS. We next assessed the association of inflammatory variables and disease-specific mortality while controlling for clinicopathological variables identified at the time of radical cystectomy. Multivariate Cox regression analyses revealed that preoperative PNI (HR, 1.54; 95\% CI, 1.08-2.80), PLR (HR, 1.62; 95\% CI, 1.07-2.46 for score 1 and HR, 3.05; 95\% CI, 1.20-7.75 for score 2), NLR (HR, 2.02; 95\% CI, 1.09-3.77), and dNLR (HR, 1.64, 95\% CI, 1.06-2.55) remained independently associated with a significantly increased risk for death from bladder cancer (Supplementary Table S2). Preoperative PNI (HR, 1.79; 95\% CI, 1.21-2.64), PLR (HR, 2.57; 95\% CI, 1.11-5.99 for score 2), NLR (HR, 2.29; 95\% CI, 1.35-3.87), and dNLR (HR, 1.74, 95\% CI, 1.19-2.53) were also independent prognostic predictors of OS (Supplementary Table S3).

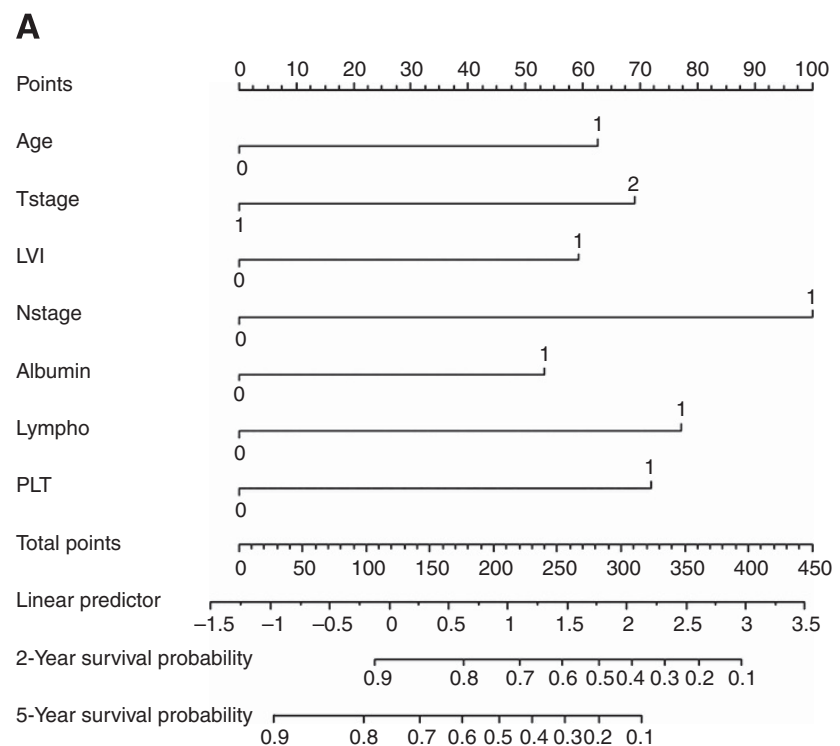

\section{DISCUSSION}

In the present study, albumin, lymphocyte count, and platelet count were independent prognostic predictors of clinical outcomes in patients with bladder. Scores based on the cellular components of SIR, such as PNI, PLR, NLR, and dNLR, were significant predictors of DSS. These findings remained significant after controlling for clinicopathological features, suggesting an independent association of SIR based on lymphocyte counts with adverse outcomes. These scores improved based on the survival prediction using AJCC staging classification alone. In contrast, CRP was not an independent prognostic predictor of clinical outcomes. In addition, SIR based on CRP, such as GPS, mGPS, and PI, was not significantly associated with survival. Therefore, CRPbased scores are not recommended for routine use in predicting survival after radical cystectomy for bladder cancer.

In addition to tumour characteristics, the host immune and inflammatory response also determines tumour progression. SIR has been determined to be an important tumour-stage independent predictor of outcome in various cancer types. In bladder cancer, an elevated NLR was associated with adverse oncological outcomes (Hermanns et al, 2014; Viers et al, 2014). However, the value of PNI, PLR, and dNLR in bladder cancer remained poorly defined, despite their potential clinical utility in preoperative risk stratification and patient counselling. In fact, of the differential white cell count parameters, the NLR has been the most extensively validated. To our knowledge, this study is the first to demonstrate that PNI, PLR, and dNLR are predictive of DSS and OS following radical cystectomy. Moreover, it is the first nomogram to include SIR in bladder cancer.

Cell-mediated immunity plays a key role in the tumour immunology of patients with cancer. SIR is a simple, cost-effective, easily reproducible, and widely available preoperative evaluation blood test. However, the mechanisms by which SIR might impact survival in cancer patients are not well defined. Active systemic inflammation may portend poor local immune response to the tumour, leading to lymph node spread and metastasis. Inhibition of apoptosis, promotion of angiogenesis, and DNA damage in response to SIR could promote tumour metastasis and progression.

\section{B}

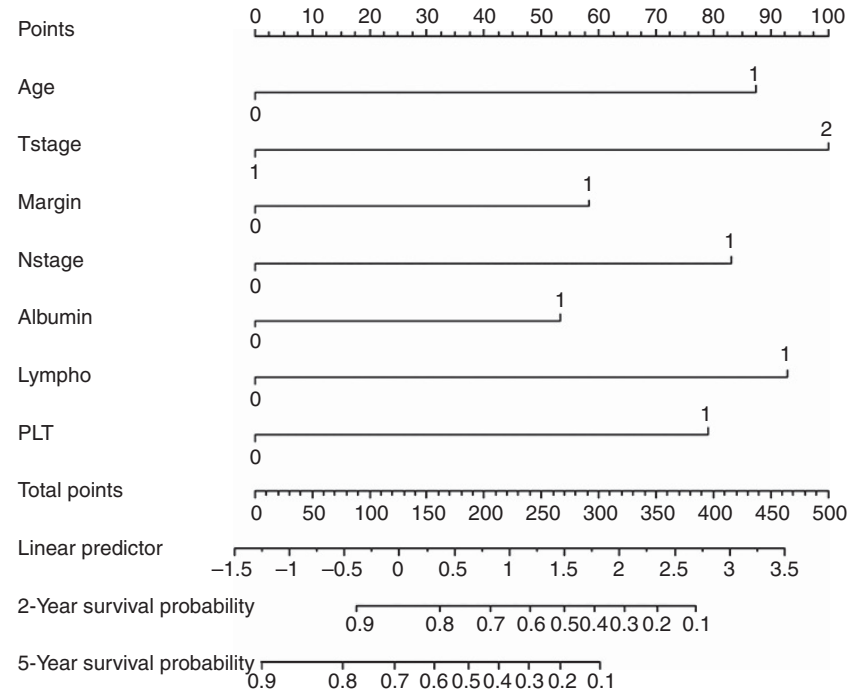

Figure 1. (A) DSS nomogram based on the multivariate model, including SIRs. (B) OS nomogram based on the multivariate model, including SIRs. age: 0 (<65 years) vs 1 ( $\geqslant 65$ years), Tstage: 1 ( $\leq \mathrm{pT} 2)$ vs 2 (T3/4), lymphovascular invasion: 0 (no) vs 1 (yes), Nstage: 0 (pN-) vs 1 (pN +), albumin: $0\left(\geqslant 35 \mathrm{gl}^{-1}\right)$ vs $1\left(<35 \mathrm{gl}^{-1}\right)$, lympho (lymphocyte count): $0\left(\geqslant 1 \times 10^{9} \mathrm{I}^{-1}\right)$ vs $1\left(<1 \times 10^{9} \mathrm{I}^{-1}\right)$, PLT (platelet count): $0\left(<400 \times 10^{9} \mathrm{I}^{-1}\right)$ vs $1\left(\geqslant 400 \times\left. 10^{9}\right|^{-1}\right)$. 
As more biomarkers are discovered and validated, efforts will focus on the combined use of multiple serum tumour markers. There is a biological rationale for using NLR, the ratio of circulating neutrophils (immune cells of innate system) to lymphocytes (immune cells of the adaptive system), as a measure of the systemic host response to evaluate the association between inflammation and cancer outcomes. Neutrophils represent $50-60 \%$ of total leukocytes and their cytoplasm is rich in granules with high toxic potential against various types of tumour cells. Circulating neutrophils have been shown to produce cytokines, such as tumour necrosis factor, interleukin-1, and interleukin-6, and to secrete pro-angiogenic vascular endothelial growth factor (Cho et al, 2009). A relative lymphocytopenia may reflect lower counts of CD4 + T-helper lymphocytes, resulting in a suboptimal lymphocyte-mediated immune response to malignancy. Thus, patients with elevated NLR have relative lymphopenia and, as a result, may exhibit a poorer lymphocyte-mediated immune response to malignancy. Absolute neutrophil and lymphocyte counts could be affected by various physiological, pathological, and physical factors, whereas NLR remains stable with respect to these factors. Thus, the stability of NLR is superior to the leukocyte subtype (Proctor et al, 2012).

dNLR was initially defined by Proctor et al (2012). This ratio employed the white cell count-neutrophil value instead of the lymphocyte value as the denominator. The stability of dNLR is similar to that of NLR because the same parameters are used to calculate them. In our study, there was small but superior prognostic value of the NLR (HR, 2.02) over the dNLR

Table 4. Discrimination estimates of risk prediction models of 5-year disease-specific and overall survival

\begin{tabular}{|c|c|c|}
\hline & \multicolumn{2}{|c|}{$\begin{array}{c}\text { Discrimination } \\
\text { (95\% confidence interval) }\end{array}$} \\
\hline & $\begin{array}{c}\text { Disease-specific } \\
\text { survival }\end{array}$ & $\begin{array}{l}\text { Overall } \\
\text { survival }\end{array}$ \\
\hline 2002 AJCC staging system & $0.720(0.673-0.768)$ & $0.703(0.664-0.743)$ \\
\hline Nomogram & $0.778(0.733-0.824)$ & $0.773(0.736-0.811)$ \\
\hline
\end{tabular}

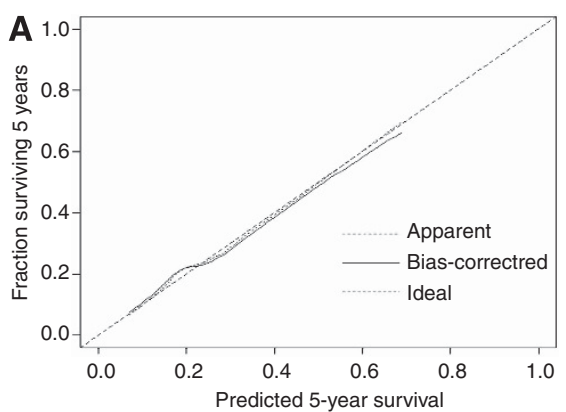

Figure 2. (A) Calibration plots for nomograms predicting 5-year DSS. (B)

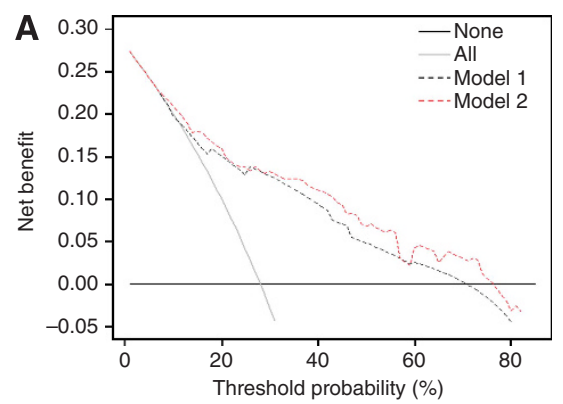

(HR, 1.64), which is consistent with previous results (Proctor et al, 2012). Although the basis of this observation is not clear, in the dNLR, the use of (white cell count-neutrophil) in the denominator is broadly mixing two cell types, lymphocytes and monocytes, with possible opposing effects in terms of predictive value.

Other prognostic factors based on lymphocyte count-based prognostic scores that are associated with cancer have been explored, including a combination of albumin and lymphocyte counts in Onodera's PNI (Forrest et al, 2003) and the combination of platelet and lymphocyte count as the PLR (McMillan, 2008). Hypoalbuminemia is introduced by high cytokine levels during the SIR. PNI is calculated using only two values: the serum albumin concentration and lymphocyte count in the peripheral blood (Onodera et al, 1984). PNI might be an effective predictive indicator for cancer prognosis, particularly digestive system carcinoma (Sun et al, 2014). Platelet aggregation and degranulation along with the consequent release of platelet-derived pro-angiogenic mediators within the tumour microvasculature also could be an important determinant of tumour growth (Sierko and Wojtukiewicz, 2004). Increased PLR was a negative prognostic marker in patients with gastric cancer, colorectal cancer, hepatocellular carcinoma, ovarian cancer, and non-small cell lung cancer, but not pancreatic cancer (Zhou et al, 2014). Our study shows that an elevated PNI or PLR is a negative predictor for DSS and OS for patients with bladder cancer who underwent radical cystectomy. However, more studies with larger sample sizes are needed to confirm the prognostic values of PNI and PLR in bladder cancer.

$\mathrm{CRP}$ is a non-specific but sensitive marker of systemic inflammation, which may be expressed selectively by tumour cells (Nozoe et al, 2003). Elevated CRP levels are indicative of poor outcomes in a variety of cancers (Koike et al, 2008; Jagdev et al, 2010; Roxburgh and McMillan, 2010) The GPS, mGPS, and PI are inflammation-based prognostic scores based on serum CRP levels. The GPS is recognised as one of the most useful scoring systems for determining long-term outcomes in patients with various cancers (Forrest et al, 2003). In the present study, acute-phase protein-based prognostic scores (GPS, mGPS, and PI) were not associated with DSS. Our results do not agree with the recent data from Dutta et al (2012), who reported that the mGPS has superior prognostic value to that of NLR in patients with gastric cancer. However, in contrast,

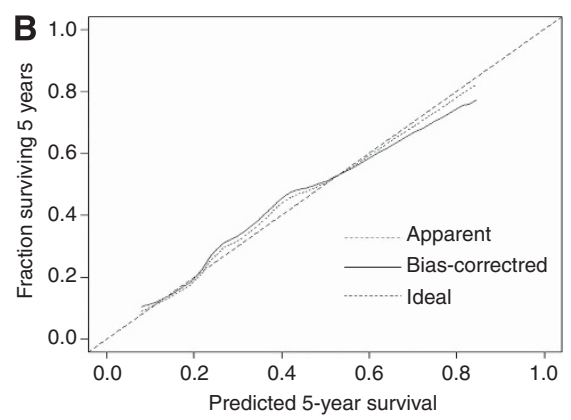

B) Calibration plots for nomograms predicting 5-year OS.

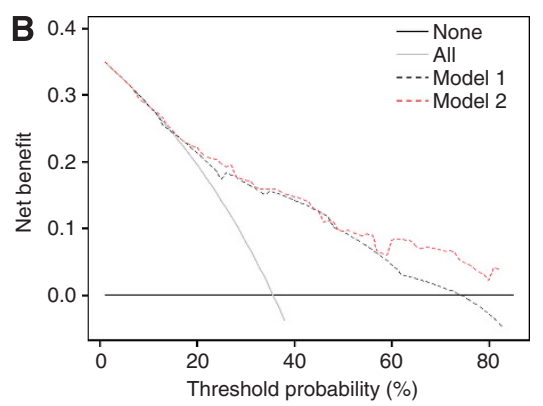

Figure 3. (A) Decision curve analyses for 5-year DSS. (B) Decision curve analyses for 5-year OS. Model 1 refers to the model without SIRs. Model 2 refers to the nomogram including SIRs. 
Mohri et al (2010) reported that the NLR was superior to the individual components of the mGPS in patients with gastric cancer. The reasons for these discrepancies remain unexplained. In this study, a single measurement was taken whereas in patients, CRP may change over time. Clinically, it would be reasonable to repeat CRP, particularly when there are changes in the patient's condition. In addition, possible confounders, such as comorbidities, were not taken into account and this might influence the results.

There are limitations to our study. First, our study is a retrospective study. Therefore, our results need to be further confirmed by a prospective study to provide a better conclusion. Second, we did not measure SIR after radical cystectomy and cannot investigate whether post-surgery improvement of SIR has a predictive value. Third, there is heterogeneity in the reported thresholds used to define an elevated SIR in the literature (Templeton et al, 2014). This may reflect variations in the host response for different disease sites and stages, or may reflect the different approaches used when determining cutoff values. Fourth, blood SIR was not compared with the extent of lymphocytic infiltration within and surrounding the cancer cells. Such histological correlations should be considered in future analyses. In addition, because we did not directly compare the prognostic value of SIR scores, the relative prognostic value of the PNI, PLR, NLR, and dNLR is not clear. More specifically, it is not clear which of these scores best predicts survival in bladder cancer. Finally, these data are from a single tertiary referral institution and thus require external validation.

In sum, the results of this study show that the prognostic value of SIR based on lymphocyte counts is superior to those based on CRP in patients with urothelial carcinoma undergoing radical cystectomy. Because SIR may be included in routine clinical assessments, the universally available SIR should be used for risk stratification of these patients.

\section{REFERENCES}

Al Murri AM, Bartlett JM, Canney PA, Doughty JC, Wilson C, McMillan DC (2006) Evaluation of an inflammation-based prognostic score (GPS) in patients with metastatic breast cancer. Br J Cancer 94(2): 227-230.

Canter D, Long C, Kutikov A, Plimack E, Saad I, Oblaczynski M, Zhu F, Viterbo R, Chen DY, Uzzo RG, Greenberg RE, Boorjian SA (2011) Clinicopathological outcomes after radical cystectomy for clinical T2 urothelial carcinoma: further evidence to support the use of neoadjuvant chemotherapy. BJU Int 107(1): 58-62.

Cho H, Hur HW, Kim SW, Kim SH, Kim JH, Kim YT, Lee K (2009) Pre-treatment neutrophil to lymphocyte ratio is elevated in epithelial ovarian cancer and predicts survival after treatment. Cancer Immunol Immunother 58(1): 15-23.

Dutta S, Crumley AB, Fullarton GM, Horgan PG, McMillan DC (2012) Comparison of the prognostic value of tumour and patient related factors in patients undergoing potentially curative resection of gastric cancer. Am J Surg 204(3): 294-299.

Forrest LM, McMillan DC, McArdle CS, Angerson WJ, Dunlop DJ (2003) Evaluation of cumulative prognostic scores based on the systemic inflammatory response in patients with inoperable non-small-cell lung cancer. Br J Cancer 89(6): 1028-1030.

Grambsch PM, Therneau TM, Fleming TR (1995) Diagnostic plots to reveal functional form for covariates in multiplicative intensity models. Biometrics 51(4): 1469-1482.

Harrell Jr FE, Lee KL, Mark DB (1996) Multivariable prognostic models: issues in developing models, evaluating assumptions and adequacy, and measuring and reducing errors. Stat Med 15(4): 361-387.

Hermanns T, Bhindi B, Wei Y, Yu J, Noon AP, Richard PO, Bhatt JR, Almatar A, Jewett MA, Fleshner NE, Zlotta AR, Templeton AJ, Kulkarni GS (2014) Pre-treatment neutrophil-to-lymphocyte ratio as predictor of adverse outcomes in patients undergoing radical cystectomy for urothelial carcinoma of the bladder. Br J Cancer 111(3): 444-451.

Hwang EC, Hwang IS, Yu HS, Kim SO, Jung SI, Hwang JE, Kang TW, Kwon DD, Park K, Ryu SB (2012) Utility of inflammation-based prognostic scoring in patients given systemic chemotherapy first-line for advanced inoperable bladder cancer. Jpn J Clin Oncol 42(10): 955-960.

Jagdev SP, Gregory W, Vasudev NS, Harnden P, Sim S, Thompson D, Cartledge J, Selby PJ, Banks RE (2010) Improving the accuracy of pre-operative survival prediction in renal cell carcinoma with C-reactive protein. Br J Cancer 103(11): 1649-1656.

Kasymjanova G, MacDonald N, Agulnik JS, Cohen V, Pepe C, Kreisman H, Sharma R, Small D (2010) The predictive value of pre-treatment inflammatory markers in advanced non-small-cell lung cancer. Curr Oncol 17(4): 52-58.

Koike Y, Miki C, Okugawa Y, Yokoe T, Toiyama Y, Tanaka K, Inoue Y, Kusunoki M (2008) Preoperative C-reactive protein as a prognostic and therapeutic marker for colorectal cancer. J Surg Oncol 98(7): 540-544.

Mantovani A, Allavena P, Sica A, Balkwill F (2008) Cancer-related inflammation. Nature 454(7203): 436-444.

McMillan DC (2008) An inflammation-based prognostic score and its role in the nutrition-based management of patients with cancer. Proc Nutr Soc 67(3): $257-262$.

Mohri Y, Tanaka K, Ohi M, Yokoe T, Miki C, Kusunoki M (2010) Prognostic significance of host- and tumor-related factors in patients with gastric cancer. World J Surg 34(2): 285-290.

Moon KC, Kim M, Kwak C, Kim HH, Ku JH (2014) External validation of online predictive models for prediction of cancer-specific mortality and all-cause mortality in patients with urothelial carcinoma of the urinary bladder. Ann Surg Oncol 21(9): 3132-3141.

Nozoe T, Korenaga D, Futatsugi M, Saeki H, Maehara Y, Sugimachi K (2003) Immunohistochemical expression of C-reactive protein in squamous cell carcinoma of the esophagus - significance as a tumor marker. Cancer Lett 192(1): 89-95.

Onodera T, Goseki N, Kosaki G (1984) [Prognostic nutritional index in gastrointestinal surgery of malnourished cancer patients]. Nihon Geka Gakkai zasshi 85(9): 1001-1005.

Proctor MJ, McMillan DC, Morrison DS, Fletcher CD, Horgan PG, Clarke SJ (2012) A derived neutrophil to lymphocyte ratio predicts survival in patients with cancer. Br J Cancer 107(4): 695-699.

Roxburgh CS, McMillan DC (2010) Role of systemic inflammatory response in predicting survival in patients with primary operable cancer. Future Oncol 6(1): 149-163.

Sierko E, Wojtukiewicz MZ (2004) Platelets and angiogenesis in malignancy. Semin Thromb Hemost 30(1): 95-108.

Stein JP, Lieskovsky G, Cote R, Groshen S, Feng AC, Boyd S, Skinner E, Bochner B, Thangathurai D, Mikhail M, Raghavan D, Skinner DG (2001) Radical cystectomy in the treatment of invasive bladder cancer: long-term results in 1,054 patients. J Clin Oncol 19(3): 666-675.

Sun K, Chen S, Xu J, Li G, He Y (2014) The prognostic significance of the prognostic nutritional index in cancer: a systematic review and meta-analysis. J Cancer Res Clin Oncol 140(9): 1537-1549.

Templeton AJ, McNamara MG, Seruga B, Vera-Badillo FE, Aneja P, Ocana A, Leibowitz-Amit R, Sonpavde G, Knox JJ, Tran B, Tannock IF, Amir E (2014) Prognostic role of neutrophil-to-lymphocyte ratio in solid tumors: a systematic review and meta-analysis. J Natl Cancer Inst 106(6): dju124.

Vickers AJ, Elkin EB (2006) Decision curve analysis: a novel method for evaluating prediction models. Med Decis Making 26(6): 565-574.

Viers BR, Boorjian SA, Frank I, Tarrell RF, Thapa P, Karnes RJ, Thompson RH, Tollefson MK (2014) Pretreatment Neutrophil-to-Lymphocyte Ratio Is Associated with Advanced Pathologic Tumor Stage and Increased Cancer-specific Mortality Among Patients with Urothelial Carcinoma of the Bladder Undergoing Radical Cystectomy. Eur Urol 66(6): 1157-1164.

Zhou X, Du Y, Huang Z, Xu J, Qiu T, Wang J, Wang T, Zhu W, Liu P (2014) Prognostic value of PLR in various cancers: a meta-analysis. PloS One 9(6): e101119.

This work is published under the standard license to publish agreement. After 12 months the work will become freely available and the license terms will switch to a Creative Commons AttributionNonCommercial-Share Alike 4.0 Unported License.

Supplementary Information accompanies this paper on British Journal of Cancer website (http://www.nature.com/bjc) 